\title{
07.3
}

\section{Фотовольтаические характеристики светодиодов с двумя последовательными $p-n$-переходами}

\author{
(C) А.А. Соколовский, В.В. Моисеев \\ Фрязинский фрилиал Института радиотехники и электроники им. В.А. Котельникова РАН, \\ Фрязино, Московская обл., Россия \\ E-mail: asokol@list.ru
}

Поступило в Редакцию 18 августа 2020 г.

В окончательной редакции 28 сентября 2020 г.

Принято к публикации 28 сентября 2020 г.

Исследованы фотовольтаические характеристики мощных ИК-светодиодов, производимых фирмой OSRAM GmbH на основе структур с двумя последовательными $p-n$-переходами. Определен спектральный диапазон работы фотовольтаических преобразователей на основе светодиодов с разной длиной волны излучения и показано, что КПД фотовольтаического преобразования у них достигает более $30 \%$ на длине волны $808 \mathrm{~nm}$. Высокое (до $2.6 \mathrm{~V}$ ) выходное напряжение таких преобразователей позволяет применять их для прямого питания маломощных электронных устройств оптическим излучением.

Ключевые слова: фотовольтаический преобразователь, напряжение холостого хода, напряжение максимальной мощности, ток короткого замыкания.

DOI: 10.21883/PJTF.2021.01.50459.18516

Известно [1], что светодиоды на основе структур GaAs/AlGaAs могут работать в качестве фотовольтаических преобразователей (ФВП) с достаточно высоким (до 45\%) КПД. Такие ФВП имеют выходное напряжение $1.2-1.25 \mathrm{~V}$ и требуют для питания электронных устройств дополнительных повышающих преобразователей напряжения. Особенностью применения светодиодов в качестве ФВП является неэффективная для фотопреобразователей форма электродов, которая при стыковке с оптическим волокном обусловливает работу ФВП с высокой плотностью оптической мощности. Последнее обстоятельство может приводить к ускоренной деградации ФВП из-за локального перегрева полупроводниковой структуры. Основной тенденцией в развитии ФВП для преобразования лазерного излучения является разработка многопереходных структур [2-4], отличающихся повышенным (до $7 \mathrm{~V}$ ) выходным напряжением. Однако как для „низковольтных“, так и для „высоковольтных“ ФВП требуется применение преобразователей напряжения, поскольку экономичное питание электронных устройств реализуется при питающем напряжении 2.0-3.3 V, которое является номинальным для подавляющего большинства цифровых и аналоговых микросхем, выпускаемых в настоящее время. В связи с этим актуальной является задача поиска и исследования характеристик недорогих ФВП с выходным напряжением более $2 \mathrm{~V}$, которые смогут работать в системах оптического питания без дополнительных преобразователей напряжения.

С этой целью были исследованы фотовольтаические параметры мощных ИК-светодиодов на основе структур с двумя последовательными $p-n$-переходами, выпускаемых фирмой OSRAM GmbH и другими фирмами (табл. 1). Предпосылками для таких исследований явились соответствие длины волны $\lambda$ излучения потен- циальному пику фоточувствительности на $\lambda=808 \mathrm{~nm}$, которая применяется в системах оптического питания, большая площадь полупроводниковой структуры, ее малое затенение контактной сеткой, малое тепловое сопротивление и высокое прямое напряжение. Все эти обстоятельства позволяли надеяться на хорошие фотовольтаические свойства данных приборов.

На рис. 1 для светодиодов OSRAM разных типов приведены нормализованные зависимости фототока структуры от длины волны падающего излучения. При измерении этих спектров источником излучения являлась галогенная лампа мощностью $70 \mathrm{~W}$, а регистрируемой величиной был фототок исследуемого светодиода, установленного на выходной щели монохроматора. При выполнении температурных измерений исследуемый светодиод помещался в термокамеру, а оптическое излучение на него подавалось от выходной щели монохроматора с помощью оптического волокна кварц-кварц с диамет-

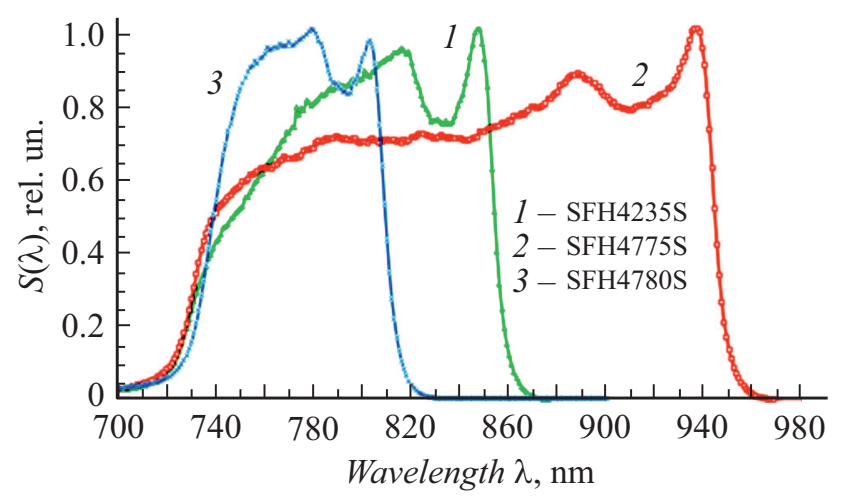

Рис. 1. Нормированные спектры фототока светодиодов OSRAM. 
Таблица 1. Некоторые характеристики светодиодов с двумя последовательными $p-n$-переходами (по данным производителей)

\begin{tabular}{c|c|c|c|c}
\hline Марка & Фирма & Длина волны, $\mathrm{nm}$ & Излучающая область, $\mathrm{mm}$ & Прямое напряжение, $\mathrm{V}$ (при $I=1 \mathrm{~A})$ \\
\hline SFH4235S & OSRAM & 850 & $1 \times 1$ & $<3.4$ \\
SFH4170S & & 850 & $0.75 \times 0.75$ & 3.25 \\
SFH4715S & & $1 \times 1$ & 3.95 \\
SFH4770S & & 850 & $1 \times 1$ & 2.3 \\
SFH4775S & & 840 & $1 \times 1$ & $3.1(0.5 \mathrm{~A})$ \\
SFH4780S & & 810 & $0.75 \times 0.75$ & $3.3(0.5 \mathrm{~A})$ \\
SFH4787S & & 850 & $0.75 \times 0.75$ & 3.15 \\
SFH4796S & & 810 & - & 3.1 \\
VSMY98145DS & Vishay & 850 & - & 3.1 \\
VSMY98525DS & & 850 & - & 3.3 \\
VSMY98545DS & & 850 & &
\end{tabular}

ром световедущей жилы $600 \mu \mathrm{m}$. Мощность излучения на выходе волокна составляла $0.4 \mathrm{~mW}$ (при $\lambda=850 \mathrm{~nm}$ ).

Характерной особенностью спектров является их двугорбый характер, связанный, по-видимому, с особенностями структуры, содержащей два последовательных $p-n$-перехода. При длине волны $\lambda=808 \mathrm{~nm}$, которая чаще всего применяется в системах оптического питания, фоточувствительность приборов составляет при комнатной температуре 70-85\% от максимальной величины.

Структуры с пиком излучения $\lambda=850 \mathrm{~nm}$ имеют при комнатной температуре максимум фототока при $\lambda \approx 848 \mathrm{~nm}$ с шириной на уровне $50 \%$ около $90 \mathrm{~nm}$. Структуры, излучающие на длине волны $\lambda=810 \mathrm{~nm}$, имеют максимум спектра фототока при $\lambda=805 \mathrm{~nm} \mathrm{и}$ ширину около 70-80 nm. Следует отметить неожиданную (по сравнению с другими светодиодами) ширину спектра фототока светодиодов с пиком излучения $\lambda=940 \mathrm{~nm}$, которая составляет более $200 \mathrm{~nm}$ и позволяет их применять в качестве ФВП с источниками с длиной волны излучения от 750 до $940 \mathrm{~nm}$.

При изменении температуры от -40 до $+60^{\circ} \mathrm{C}$ (диапазон рабочих температур светодиодов) спектр фототока линейно смещается с крутизной $0.25-0.3 \mathrm{~nm} /{ }^{\circ} \mathrm{C}$, что практически совпадает со смещением спектра излучения, приведенным в справочных данных. Фоточувствительность приборов на длине волны $808 \mathrm{~nm}$ имеет пологий максимум при температуре $-10^{\circ} \mathrm{C}$ и незначительно спадает на краях температурного диапазона.

На рис. 2 показано смещение нормализованного спектра фототока светодиода марки SFH4235S с изменением температуры. Из приведенного рисунка следует, что при уменьшении фототока не более чем на $30 \%$ спектральным интервалом работы ФВП на основе светодиодов с длиной волны излучения $850 \mathrm{~nm}$ в промышленном диапазоне температур будет область 800-835 nm.

Для последующих исследований светодиоды сопрягались со стандартным многомодовым волокном $62.5 / 125 \mu \mathrm{m}$. Светодиод, установленный с зазором $1.5 \mathrm{~mm}$ относительно торца волокна, юстировался до получения максимального тока короткого замыкания

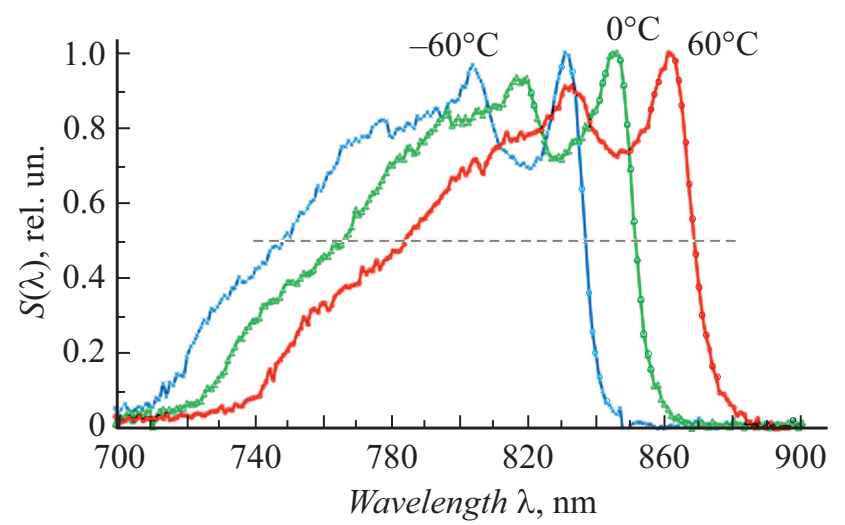

Pис. 2. Смещение спектра фототока с температурой.

при мощности излучения $100 \mathrm{~mW}$ и в таком положении фиксировался пайкой. При нулевом зазоре, несмотря на увеличение тока короткого замыкания, КПД фотопреобразования уменьшается за счет того, что вольт-амперная характеристика приобретает вид ступенчатой кривой, в результате чего существенно снижаются коэффициент заполнения (fill factor, $f f$ ) и напряжение максимальной мощности.

На рис. 3 показаны вольт-амперные характеристики (BAX) светодиодов OSRAM при их засветке излучением с длиной волны $808 \mathrm{~nm}$ при комнатной температуре. BAX измерялась при изменении сопротивления нагрузки ФВП в пределах $0-10 \mathrm{k} \Omega$. На основе приведенных зависимостей можно выделить три группы приборов: светодиоды, излучающие на длине волны $850 \mathrm{~nm}$, имеют напряжение холостого хода в фотовольтаическом режиме $2.5 \mathrm{~V}$, излучающие на длине волны $940 \mathrm{~nm}-2.3 \mathrm{~V}$, излучающие на длине волны $810 \mathrm{~nm}-2.7 \mathrm{~V}$.

Обращает на себя внимание необычный для фотовольтаического преобразователя вид ВАХ для светодиода SFH4780S. Положительная производная зависимости $I(V)$ в области напряжений 0-2 V может быть связана, по нашему мнению, с тем, что изначально излучение, 
Таблица 2. Фотовольтаические характеристики светодиодов OSRAM при различной мощности излучения

\begin{tabular}{c|c|c|c|c|c|c|c|c|c|c|}
\hline \multirow{2}{*}{ LED } & \multicolumn{2}{|c|}{$\eta, \%$} & \multicolumn{2}{c|}{$U_{o c}, \mathrm{~V}$} & \multicolumn{2}{c|}{$U_{m p p}, \mathrm{~V}$} & \multicolumn{3}{c|}{$I_{s c}, \mathrm{~mA}$} & \multicolumn{2}{c}{$f f$} \\
\cline { 2 - 11 } & $100 \mathrm{~mW}$ & $400 \mathrm{~mW}$ & $100 \mathrm{~mW}$ & $400 \mathrm{~mW}$ & $100 \mathrm{~mW}$ & $400 \mathrm{~mW}$ & $100 \mathrm{~mW}$ & $400 \mathrm{~mW}$ & $100 \mathrm{~mW}$ & $400 \mathrm{~mW}$ \\
\hline SFH4235S & 35.00 & 32.40 & 2.53 & 2.55 & 2.295 & 2.24 & 15.88 & 59.2 & 0.87 & 0.86 \\
SFH4715S & 35.58 & 29.30 & 2.53 & 2.54 & 2.285 & 2.31 & 16.24 & 52.65 & 0.87 & 0.85 \\
SFH4770S & 34.82 & 29.36 & 2.53 & 2.50 & 2.07 & 1.94 & 21.86 & 67.78 & 0.63 & 0.69 \\
SFH4775S & 42.23 & 32.85 & 2.29 & 2.30 & 2.067 & 2.09 & 23.72 & 86.62 & 0.78 & 0.66 \\
SFH4780S & 46.48 & 38.98 & 2.73 & 2.75 & 2.441 & 2.51 & 20.45 & 64.1 & 0.85 & 0.86
\end{tabular}

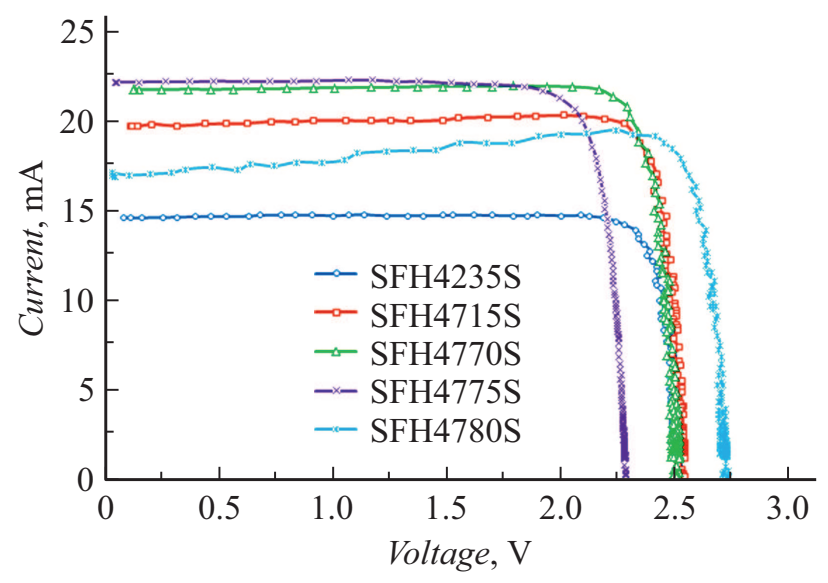

Рис. 3. ВАХ светодиодов в фотовольтаическом режиме, измеренные при комнатной температуре, при их засветке непрерывным излучением мощностью $100 \mathrm{~mW}$ на длине волны $808 \mathrm{~nm}$.

подаваемое на полупроводниковую структуру, попадает на крутой склон спектральной характеристики (рис. 1). При разогреве структуры падающим излучением спектр фоточувствительности смещается в длинноволновую область, что видно из рис. 2 на примере светодиода SFH4235S. В результате этого смещения за время измерения около $2 \mathrm{~min}$ увеличивается токовая чувствительность структуры на длине волны $808 \mathrm{~nm}$, что и приводит к формированию нарастающего участка ВАХ. На других образцах светодиодов, у которых длина волны $808 \mathrm{~nm}$ попадает в середину спектрального диапазона фоточувствительности, таких особенностей BAX не наблюдалось.

Исходя из измеренных ВАХ (измерено более 20 образцов светодиодов различных типов) определены основные фотовольтаические параметры этих приборов: эффективность преобразования $\eta$, напряжение холостого хода $U_{o c}$, напряжение максимальной мощности $U_{m p p}$, ток короткого замыкания $I_{s c}$ и последовательное сопротивление $R_{s}$. Последовательное сопротивление рассчитывалось по формуле [5]:

$$
R_{s}=\frac{\Delta U}{\Delta I}-\frac{2 k T}{e I_{s c}}
$$

где параметр $\frac{\Delta U}{\Delta I}$ определяется в области $I=0$. Характерные значения последовательного сопротивления составляют $1-3 \Omega$. Для большинства исследованных приборов коэффициент заполнения лежит в пределах 0.85-0.88 при мощности излучения до $150 \mathrm{~mW}$ и уменьшается до значения 0.76-0.86 при мощности $400 \mathrm{~mW}$. Заметим, что снижение коэффициента заполнения обусловлено главным образом изменением формы ВАХ, которая может принимать вид ступенчатой кривой при большой мощности засветки.

В табл. 2 приведены фотовольтаические характеристики светодиодов OSRAM, усредненные по трем-пяти образцам каждого типа, измеренные при комнатной температуре с источником излучения на длине волны $808 \mathrm{~nm}$, работающим в непрерывном режиме.

Из приведенной таблицы видно, что исследуемые светодиоды обладают высоким (> 2.5 V) выходным напряжением и хорошим КПД, достигающим 46\%, что позволяет их применять для питания оптическим излучением маломощных (до $100 \mathrm{~mW}$ ) электронных устройств. При этом в промышленном диапазоне температур светодиоды с длиной волны излучения $810 \mathrm{~nm}$ могут применяться в качестве ФВП совместно с источниками излучения на длину волны 770-780 nm. Эффективность ФВП на основе светодиодов SFH4775S может быть увеличена при использовании источников с длиной волны излучения $915 \mathrm{~nm}$ (рис. 1).

Напряжение холостого хода линейно изменяется с температурой с коэффициентом примерно $-3 \mathrm{mV} /{ }^{\circ} \mathrm{C}$, что соответствует температурному ходу прямого напряжения светодиодов. Напряжение точки максимальной мощности также линейно зависит от температуры и может быть вычислено из соотношения $U_{\text {mp }} \approx 2.355-2.7 \cdot 10^{-3} T$, где $T-$ температура в градусах Цельсия. Экспериментальные значения в диапазоне температур $\pm 60^{\circ} \mathrm{C}$ отличаются от расчетных не более чем на $10 \%$.

Эффективность фотовольтаического преобразования в диапазоне температур от -60 до $+40^{\circ} \mathrm{C}$ изменяется не более чем на $2 \%$ и дополнительно уменьшается еще на $5 \%$ при температуре $+60^{\circ} \mathrm{C}$.

Таким образом, в работе показано, что светодиоды фирмы OSRAM на основе структур AlGaAs с двумя последовательными $p-n$-переходами обладают КПД фотоэлектрического преобразования более $30 \%$ на длине волны $808 \mathrm{~nm}$. Высокое выходное напряжение таких ФВП позволяет их применять для питания маломощ- 
ных электронных устройств оптическим излучением в промышленном диапазоне температур без применения дополнительных преобразователей напряжения.

\section{Финансирование работы}

Работа выполнена в рамках государственного задания.

\section{Конфликт интересов}

Авторы заявляют, что у них нет конфликта интересов.

\section{Список литературы}

[1] А.А. Соколовский, Письма в ЖТФ, 44 (4), 57 (2018). DOI: 10.21883/PJTF.2018.08.45967.17154 [Пер. версия: 10.1134/S1063785018040259].

[2] В.М. Андреев, Н.А. Калюжный, В.М. Лантратов, С.А. Минтаиров, А.С. Гудковских, Многопереходный преобразователь. Патент РФ № 2442242, Бюл. № 4 (2012).

[3] S. Fafard, D.P. Masson, Transducer to convert optical energy to electrical energy. Patent US 2015/0162478 (2015).

[4] http://www.mhgopower.com/images/PPC_Product_Brief_Rev_ 2.4_03-12-2020_EN.pdf

[5] М.М. Колтун, Оптика и метрология солнечных элементов (Наука, М., 1985). 